\title{
O CARÁTER ÚNICO DE MORRO VERMELHO NA REGIÃO METROPOLITANA DE BELO HORIZONTE
}

THE UNIQUENESS OF MORRO VERMELHO IN BELO HORIZONTE'S METROPOLITAN REGION

\author{
Simone Marques de Sousa Safe* \\ Luciane Raposo Faquineli** \\ Staël de Alvarenga Pereira Costa***
}

\begin{abstract}
RESUMO
A expressão histórica e cultural de uma sociedade no ambiente físico permite a contemplação da vivência da comunidade em diversos períodos morfológicos, conferindo ao habitat uma identidade própria. $\bigcirc$ presente artigo tem como objetivo contrapor a ausência de tecido urbano em Morro Vermelho, distrito do município de Caeté, Minas Gerais, à evolução urbana da Região Metropolitana de Belo Horizonte, na qual está inserido, buscando compreender os motivos pelos quais essa ocupação territorial estagnou. Além disso, o trabalho visa aplicar os conceitos da Escola Italiana e da Escola Inglesa de Morfologia Urbana, comparando a análise feita no Distrito de Morro Vermelho em 2013 com a formação de Belo Horizonte, quando ainda era Arraial Curral Del Rei. Para o desenvolvimento deste artigo foi realizado um trabalho de campo no distrito de Morro Vermelho e posterior análise dos dados coletados utilizando os conceitos de Morfologia Urbana.
\end{abstract}

Palavras-chave: Morfologia urbana. Região Metropolitana de Belo Horizonte. Protonúcleo. Morro Vermelho.

\begin{abstract}
The expression of a historical and cultural society in the physical environment, allows an approach with the community experience in various morphological periods, granting to the habitat a distinct identity. The article's objective is to understand the absence of urban fabric in Morro Vermelho, district of Caeté, in Minas Gerais, in contradistinction with the evolution of the urban Metropolitan Region of Belo Horizonte, in which it is inserted, seeking to understand the reasons for which this territorial occupation has stagnated. In addition, the work aims to apply the concepts of the Italian and the English Schools of Urban Morphology, comparing the analysis of Morro Vermelho's District, done in 2013, with the formation of Belo Horizonte, when it was still a country site named Curral Del Rei. For this article's development it was necessary a site visit in Morro Vermelho and a later analysis of the data collected using the concepts of Urban Morphology. Keywords: Urban Morphology. Belo Horizonte's Metropolitan Region. Proto Nucleus. Morro Vermelho.
\end{abstract}

* Graduada em Arquitetura pela Universidade Católica de Minas Gerais (PUC Minas). Mestranda em Ambiente Construído e Patrimônio Sustentável pela Escola de Arquitetura da Universidade Federal de Minas Gerais (UFMG).

simonesafe@globo.com

** Graduada em Arquitetura pela Escola de Arquitetura da Universidade Federal de Minas Gerais (UFMG). lufaquineli@gmail.com

*** Arquiteta e urbanista pela Universidade Federal de Minas Gerais (UFMG). Master of Arts em Design Urbano pela Oxford Brookes University. Doutora em Estruturas Ambientais Urbanas pela Faculdade de Arquitetura e Urbanismo da Universidade de São Paulo (FAUUSP). Professora do Departamento de Urbanismo da Escola de Arquitetura da UFMG. Coordenadora do Laboratório da Paisagem da Escola de Arquitetura da Universidade Federal de Minas Gerais (EA-UFMG).

staelalvarenga@gmail.com 


\section{INTRODUÇÃO}

A identificação de um tecido urbano considera as características gerais de seus elementos construídos, o modelo de assentamento no solo e o número de pavimentos resultantes deste modelo. Segundo Levy (1999), há "tipos" que reúnem as principais características formais e podem ser reconhecidos como os que melhor representam os produtos naquele determinado período de tempo.

O presente artigo tem como objetivo compreender as características morfológicas de Morro Vermelho, distrito do município de Caeté, Minas Gerais, visando à contraposição da sua forma urbana com a Região Metropolitana de Belo Horizonte, na qual está inserido, na busca do entendimento dos motivos pelos quais essa ocupação territorial estagnou.

Anne Vernez Mouldon (1997) alega que os atributos das formas urbanas e de seus elementos refletem não somente um período na história, como também as condições socioeconômicas existentes na época da sua formação, que seriam compostas por tecidos urbanos.

Além disso, o trabalho visa à aplicação dos conceitos da Escola Italiana e da Escola Inglesa de Morfologia Urbana comparando o Distrito Morro Vermelho, nos dias de hoje, com a formação de Belo Horizonte, quando ainda era Arraial Curral Del Rei. Esse procedimento metodológico auxilia a análise da paisagem como "[...] expressão morfológica das diferentes formas de ocupação e consequente transformação do ambiente em um determinado tempo". (MACEDO, 1999).

\section{CAETÉ E A REGIÃO METROPOLITANA DE BELO HORIZONTE (RMBH)}

A criação de Belo Horizonte teve como intenção construir uma cidade moderna, capaz de absorver uma estrutura administrativa, já que a antiga capital, Ouro Preto, não tinha possibilidade de expansão devido ao relevo acidentado. $\bigcirc$ local escolhido foi o Arraial Curral Del Rei, totalmente demolido para possibilitar a criação de uma cidade planejada em uma malha ortogonal estruturada em três zonas de ocupação: a Zona Urbana, a Zona Suburbana e a Zona Rural (figura 1).

O objetivo inicial era uma ocupação no eixo norte-sul, entretanto "[...] a implantação de um ramal ferroviário no sentido oeste, paralelo ao Ribeirão Arrudas, induziu nova tendência de ocupação urbana, que referenciava a antiga ocupação do arraial do Curral Del Rei". (PEREIRA COSTA, 2004, p. 42). 


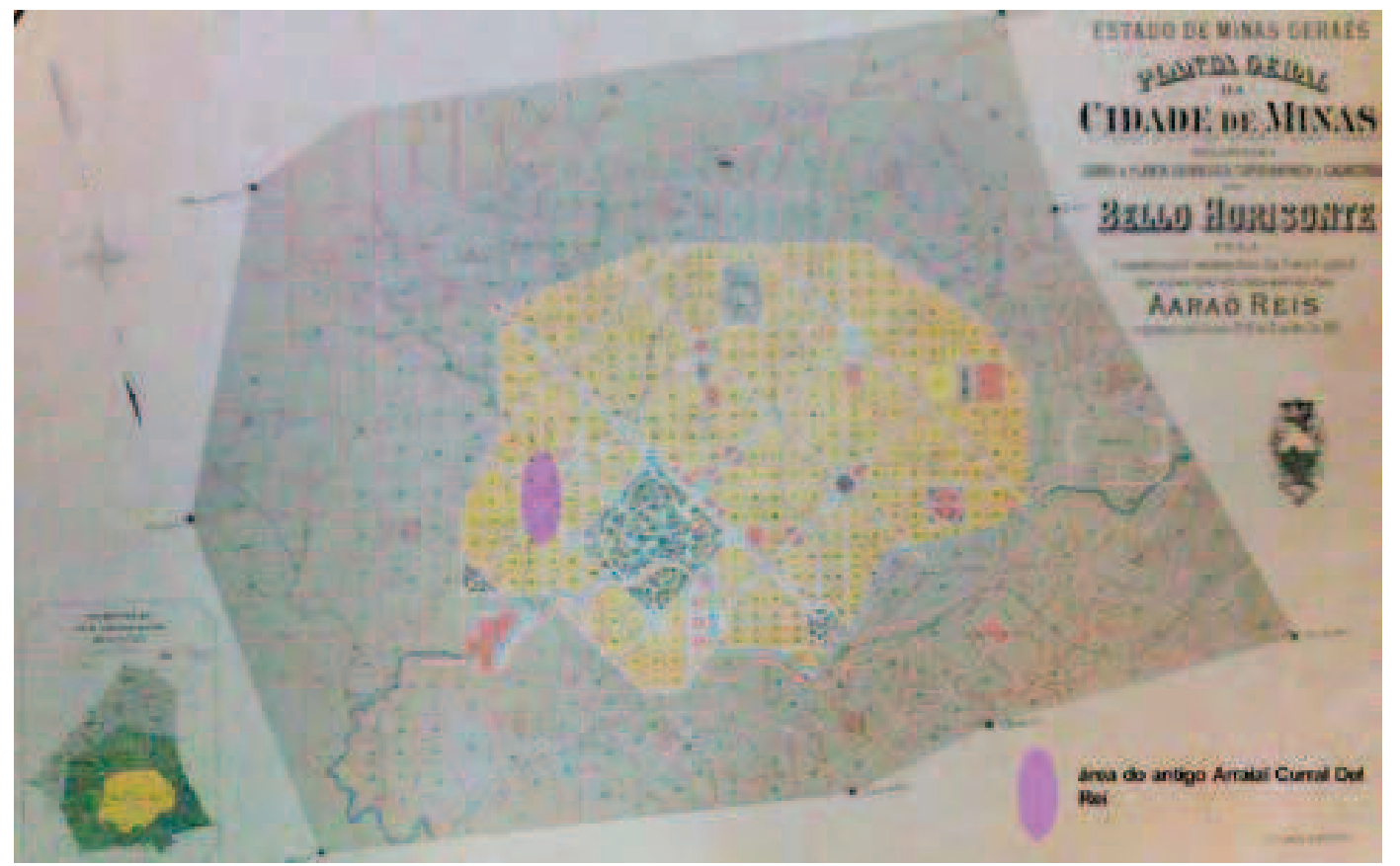

Figura 1 Planta da cidade de Belo Horizonte, delimitando área do antigo Arraial Curral Del Rei. Araão Reis - 1897. Fonte: Panorama de Belo Horizonte: atlas histórico. Sistema Estadual de Planejamento. Fundação João Pinheiro. Centro de Estudos Históricos e Culturais. Coleção Centenário. Belo Horizonte - 1997.

A metropolização de Belo Horizonte, em 1973, ocorrev em resposta à necessidade de desenvolvimento planejado da região, devido às elevadas taxas de crescimento demográfico estimuladas pela industrialização. Na época de sua criação, a RMBH era composta pelos municípios de Belo Horizonte, Betim, Caeté, Contagem, Ibirité, Lagoa Santa, Nova Lima, Pedro Leopoldo, Raposos, Ribeirão das Neves, Rio Acima, Sabará, Santa Luzia e Vespasiano. Em 2013, a Região Metropolitana conta com 34 municípios, apresentando expansão significativa no vetor oeste, com a implantação de centros industriais, e no vetor norte/sul, com as siderúrgicas, fábricas de cimento e calcário, e do aeroporto.'

No vetor leste há pequenas expansões fragmentadas, devido, principalmente, à barreira natural constituída pela serra do Curral. Nesse vetor, encontra-se a cidade de Caeté, a aproximadamente $35 \mathrm{~km}$ de Belo Horizonte, elevada à categoria de cidade em 1865. Em 2013, além da sede, Caeté possui quatro distritos: Morro Vermelho, Antônio Santos, Penedia e Roças Novas.

De acordo com o último CENSO (IBGE, 2010), o município conta com aproximadamente 40 mil habitantes, sendo que a maioria da população vive na zona urbana.

TEIXEIRA, Maria Cristina Villefort et al. Os elementos tipomorfológicos das bordas metropolitanas de Belo Horizonte. Relatório final do projeto de pesquisa financiado pela Fundação de Amparo à Pesquisa do Estado de Minas Gerais (FAPEMIG). Universidade Federal de Minas Gerais, Escola de Arquitetura, Belo Horizonte, 2012. 


\section{Região Metropolitana de Belo Horizonte Aglomerado urbano - 1990}

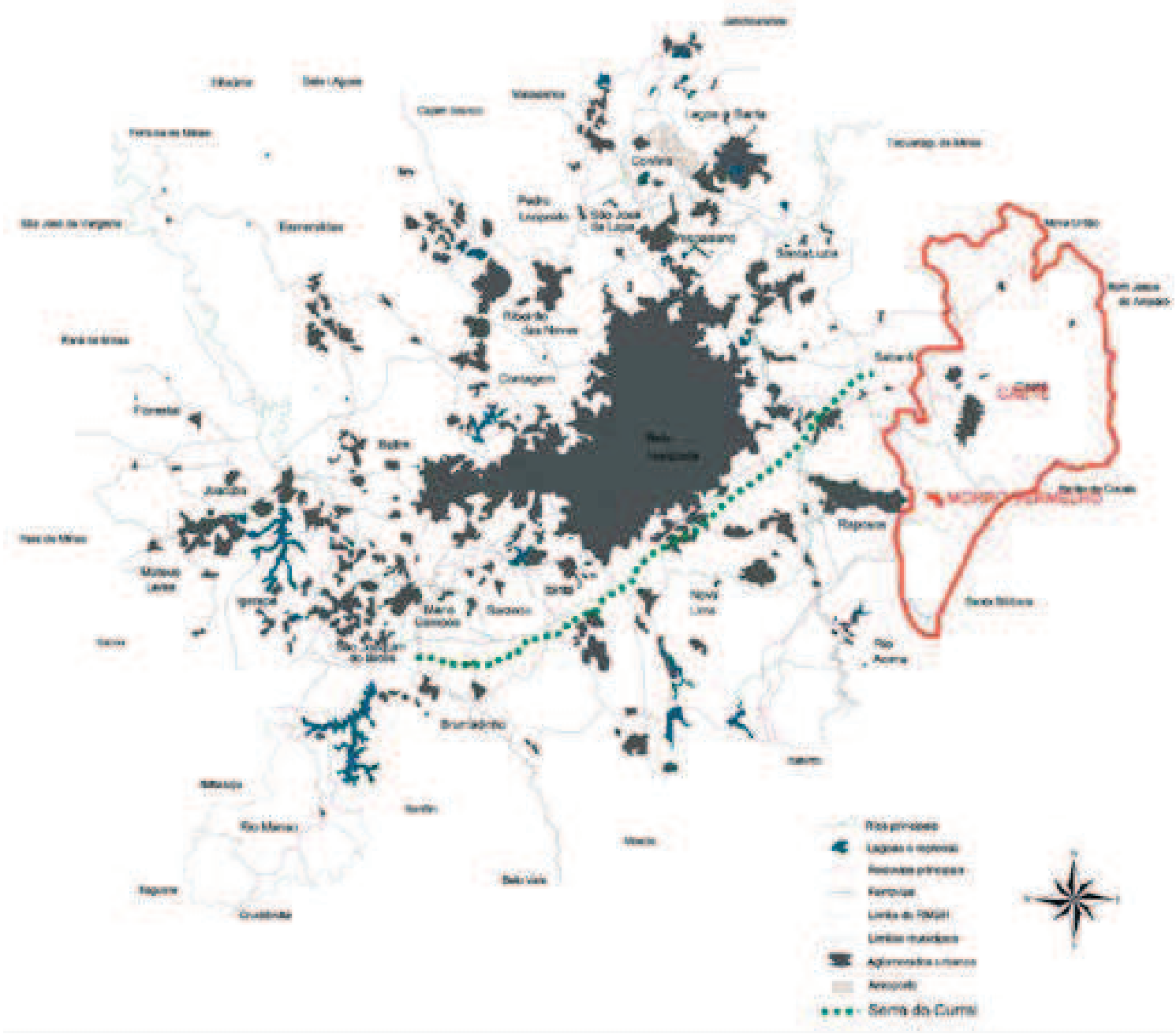

Figura 2 Ocupação nos municípios da Região Metropolitana de Belo Horizonte - 1990. Fonte: Produzida pelas autoras em 2013, com base em Pereira Costa (2004, p. 50).

\section{PROCEDIMENTOS METODOLÓGICOS}

Para o desenvolvimento deste artigo foi realizado um trabalho de campo no distrito de Morro Vermelho e posterior análise da forma urbana - utilizando os conceitos das Escolas Inglesa e Italiana de Morfologia Urbana.

A Escola Inglesa de Morfologia Urbana, desenvolvida pelo geógrafo Michael R. G. Cozen², consiste na análise de três elementos: plano urbano; tecido urbano; uso do solo. O plano urbano, elemento analisado neste artigo, é o traçado original da cidade, cuja análise se baseia na inter-relação entre o lugar, o sistema vário, o padrão de parcelamento dos lotes e a implantação das edificações nos mesmos.

O geógrafo alemão M.R.G. Conzen, um dos primeiros investigadores interessados no estudo da forma urbana, imigrou para a Inglaterra durante a Segunda Guerra Mundial, tendo como principal contribuição o estudo sobre Alnwick (1960). 
O plano urbano de Morro Vermelho corresponde a um caminho tronco, que liga a Igreja do Rosário, a lgreja Matriz e o chafariz (figura 4).

A Escola Italiana de Morfologia Urbana, criada pelo arquiteto Muratori ${ }^{3}$ e, posteriormente desenvolvida por seguidores como Caniggia e $\mathrm{Maffei}^{4}$, visa à compreensão da realidade atual como síntese da história coletiva, que pode ser examinada criticamente, através da unidade habitacional mais recorrente, denominada pelo autor como "tipo" - uma espécie de arquétipo inerente à mente do indivíduo de uma época, no qual a forma é a síntese expressiva das realidades estrutural, funcional e ambiental, que embasam a análise tipológica e o seu processo evolutivo no tempo, conhecido como "processo tipológico".

Esse processo evolutivo é o reconhecimento da existência do tipo e das suas mudanças consequentes ao longo do tempo. É um suceder-se de mutação e distinção temporal com relativa influência espacial mútua. As principais mudanças ocorrem na implantação, e/ou na ocupação e/ou na fachada. Os processos tipológicos de mutação recebem as conceituações de diatópicos, sincrônicos e diacrônicos.

A diversificação sincrônica refere-se à aplicação do mesmo tipo repetidamente. A diversificação diatópica, à aplicação de um tipo que corresponde à consciência espontânea ${ }^{5}$ de determinada área cultural, em outra região geográfica, cuja consciência espontânea difere da primeira, provocando, assim, uma variação regional geográfica. A diversificação diacrônica, que atua a partir da observação sobre a diversificação cronológica dos tipos numa mesma área, pode compararse a algumas variáveis apresentadas por diferenciações encontradas nos tipos contemporâneos que se seguiram.

Em Morro Vermelho, o "tipo básico" mais recorrente é o que apresenta largura de fachada em torno de 10 a 12 metros. Foram encontrados, também, tipos edilícios, com variação de fachada de 6 a 8 metros e 13 a 15 metros. As variações são do tipo diacrônica e caracterizam-se, também, pelo uso de novos materiais - janelas, portas, telhados e revestimentos fachada.

3 O arquiteto Saverio Muratori, nascido em Modena (ltália), em 1910, é reconhecido como um dos primeiros investigadores da Morfologia Urbana. Sua vida pública pode ser reunida em dois períodos. O primeiro iniciou-se após sua formatura na Scuola Superiore di Architettura di Roma, no período situado entre 1933 a 1946, cuja prática profissional se desenvolveu de acordo com o conteúdo correspondente ao âmbito cultural arquitetônico da Itália, antes da Segunda Guerra Mundial. No segundo período, de 1947 a 1963 (pós-guerra), Muratori emergiu, progressivamente, como teórico e docente de arquitetura, buscando a superação do "Moderno".

4 Gianfranco Caniggia e Gian Luigi Maffei foram assistentes de Muratori, que, depois da sua morte, viram-se obrigados a se deslocarem para outras faculdades, onde continuaram a desenvolver as ideias de seu mentorporém com base nas próprias experiências pessoais. A principal obra estudada pelas autoras é Architectural composition and building typology: interpreting basic building. Firenze: Alinea editrice srl. 1979.

5 A consciência espontânea descreve atitudes de decisão tomadas pelos seres humanos que não pensam duas vezes e decidem por si só suas escolhas. Se pensarmos em edificações espontâneas, estas corresponderão aos fazeres imediatos, feitos pelos próprios usuários, sem interpretação de profissionais ou de técnicas. Esses fazeres são consequentes de uma cultura edilícia, espontaneamente adquiridos e repassados num momento determinado na área cultural. Interpretating Basic Building, 2002, p. 43. 


\section{MORRO VERMELHO: DE ARRAIAL A DISTRITO}

O arraial de Morro Vermelho parece ter se iniciado nos primórdios da ocupação da região de Caeté, cuja origem remete ao século XVII, e deve seu surgimento ao extinto arraial de Vira Copos. A informação mais antiga encontrada a respeito sobre moradores naquela região consta do Lançamento de despesas da fazenda e lavra do Morro Vermelho, datado entre 1768 a $1776 .^{6}$

A ocupação acompanhou as áreas de exploração aurífera - primeiramente no Ribeirão Comprido, que corta o povoado, e no rio Vermelho. Depois, nas encostas dos morros do entorno.7 A presença da Matriz de N. Sra. de Nazaré ${ }^{8}$ e da Capela do Rosário9, iniciadas em meados do século XVIII, nos mesmo locais das primitivas ermidas, são reflexos da riqueza do lugar durante o Ciclo do Ouro.

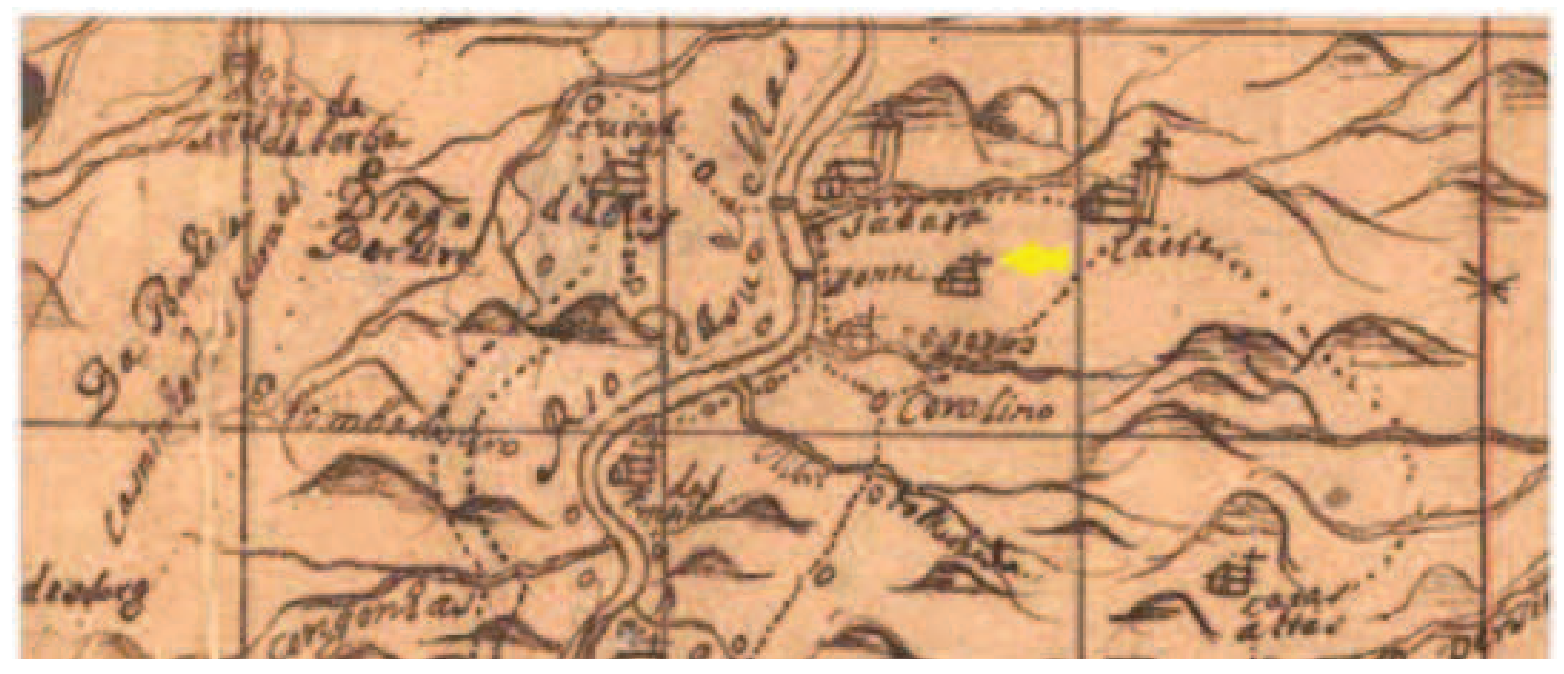

Figura 3 Destaque de vilas, povoados e rotas próximos de Caeté. A seta amarela mostra uma capela sem identificação, que, possivelmente, seria o primitivo templo de N. Sra. de Nazaré de Morro Vermelho. Disponível em: <http://www.wdl.org/pt/item/954/>. Acesso em: mai. 2013.

Como em muitos arraiais nascidos nas Minas do Período Colonial, a capela do Rosário ("dos negros") aparece em contraposição à Matriz ("dos brancos"), conformando uma das partes principais do caminho tronco do Arraial de Morro Vermelho. Esse caminho começa na Capela do Rosário (2), passa pela rua Evangelista Marques, pelo Largo da Matriz (1), segue pela rua Dr. Antônio Mourão Guimarães e termina no único chafariz (3) existente no distrito.

6 Arquivo Público Mineiro. Disponível em: <http://www.siaapm.cultura.mg.gov.br/modules/cc/brtacervo. php? cid=924>. Acesso em: jul. 2013.

7 Informações extraídas do dossiê de tombamento Capela do Rosário, 2004.

8 Tombada pelo Instituto do Patrimônio Histórico e Artístico Nacional (IPHAN) em 9 de maio de 1950, sob inscrição n ${ }^{\circ} 362$ do Livro de Belas Artes, processo 0397-T. Disponível em: <http://www.iphan.gov.br/ans.net/ tema_consulta.asp?Linha=tc_belas.gif\&Cod=1283>. Acesso em: jul. 2013.

9 Tombada pelo IPHAN em 9 de maio de 1950, sob a inscrição n 363 do Livro de Belas Artes, processo 0408 T-49. Disponível em:

<http://www.iphan.gov.br/ans.net/tema_consulta.asp?Linha=tc_belas.gif\&Cod=1282>. Acesso em: jul. 2013. 


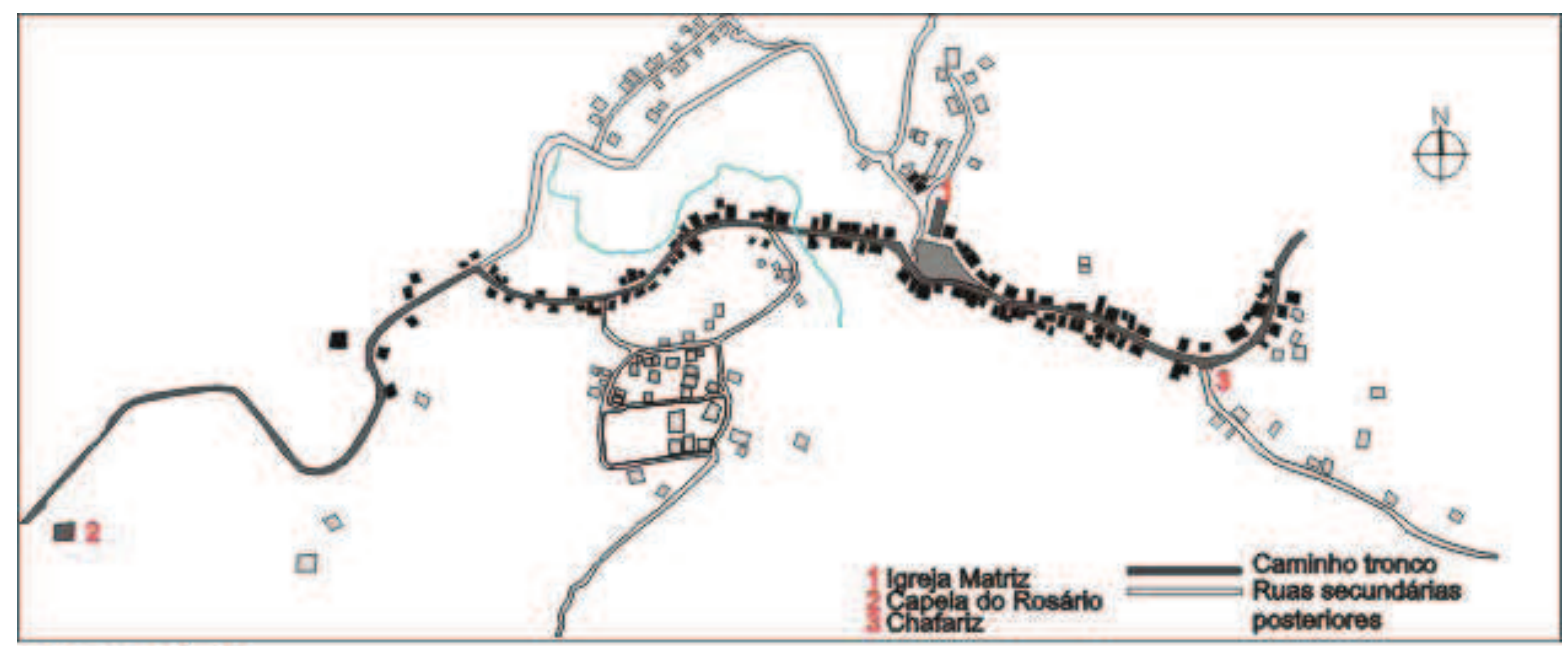

ESCALA GRAFICA

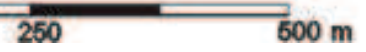

Figura 4 Plano Urbano de Morro Vermelho.

Fonte: Produzido pelas autoras, com base em mapa da Superintendência de Desenvolvimento da Região

Metropolitana (PLAMBEL) de Morro Vermelho - 1977 - e em vista aérea extraída do Google Earth em julho de 2013.

A partir da segunda metade do século XVIII, com a escassez do ouro de aluvião, os centros mineradores entraram gradativamente em crise. Algumas das antigas vilas do ouro se reinventaram com a agropecuária e o comércio, mas a maioria perdeu importância e moradores, dentre elas Vila Nova da Rainha (Caeté) e o Arraial de Vira Copos (Morro Vermelho).

Estudos históricos apontam o comércio como contribuidor para amenizar os efeitos da decadência, uma vez que Morro Vermelho está localizado entre importantes vilas coloniais, como Sabará, Raposos, Curral Del Rei, Catas Altas e Santa Bárbara. Além disso, a condição de entreposto comercial favorecia o trânsito das tropas e dos tropeiros, que integravam as regiões da província e da Colônia, dinamizando a economia.

\section{A CIDADE DE CAETÉ E O DISTRITO DE MORRO VERMELHO}

A retomada do crescimento econômico de Caeté ocorreu no final do século XIX, com a industrialização, especialmente dos setores de cerâmicas e carvoaria, destacando-se a Cerâmica Nacional ou Cerâmica João Pinheiro, fundada em 1893, e a "Usina Gorceix", da Cia. Ferro Brasileiro, instalada em 1931 na serra da Piedade, que mantém áreas de reflorestamento especificamente destinadas a esse fim - uma delas em Morro Vermelho. (PLAMBEL, 1980).

Segundo o termo de referência de Caeté (PLAMBEL, 1980), em torno dos anos 1980 o setor secundário apresenta, junto a Refratários João Pinheiro e à Cia Ferro Brasileiro, estabelecimentos de menor porte, que se juntaram a eles formando o 
quadro industrial do município e proporcionando certa estabilidade econômica ao distrito. São eles: a Argamasit (aditivos para argamassa empregados na construção civil), a Isomec (máquinas distribuidoras de adubos orgânicos) e a Rochalar Ltda. (panelas, caldeirões, pratos de alumínio). A economia conta, também, com o cultivo de eucalipto, com a apicultura, a produção de quitandas e o artesanato em bordados.

Em 1837, Morro Vermelho contava com 805 habitantes - e não parece ter crescido muito até 1842, quando o distrito foi criado. De acordo com termo de referência de Caeté (PLAMBEL, 1980), a população de Morro Vermelho apresenta decréscimo de 1.184 (1970) para 1.105 mil habitantes (1980), justamente na época em que Caeté apresenta acréscimo de população, em torno de 1,2\%, por conta da presença dos novos estabelecimentos econômicos.

Os distritos mais próximos a Caeté vivem, então, a perda de seus habitantes, devido a essa proximidade. Tal fato continuou ocorrendo até os dias presentes, como apresenta o censo de 2010, quando Morro Vermelho apresentou 938 habitantes. (IBGE, 2010). Apenas os distritos mais distantes, como Antônio dos Santos e Roças Novas, apresentaram acréscimo populacional.

Hoje, Morro Vermelho requer atenção especial, por ser considerado, potencialmente, o núcleo urbano mais diretamente impactado pelas atividades de mineração da VALE, o que potencializa a retomada do crescimento populacional no distrito, pela previsão futura de empregos a serem gerados na região. ${ }^{10}$

As futuras instalações industriais do Projeto Mina Apolo situam-se a cerca de $10 \mathrm{~km}$ do distrito. Estão previstos investimentos para a implantação e expansão de minas e usinas de beneficiamento de minério de ferro no Estado. Os recursos somam o segundo maior investimento da VALE em Minas Gerais desde a implantação da mina de Brucutu, em outubro de 2006.

Os projetos abrangem sete municípios: Itabira, Itabirito, Barão de Cocais, Caeté, Raposos, Rio Acima e Santa Bárbara. Os recursos estão distribuídos em três empreendimentos: a Mina Apolo e as usinas Conceição-ltabiritos e Vargem GrandeItabiritos. Após implantação, os projetos envolverão investimentos de $R \$ 9,4$ bilhões, gerando cerca de 9.930 empregos diretos e indiretos na construção. Na operação, serão gerados aproximadamente outros 2,2 mil empregos, aumentando a produção de minério de ferro da VALE, em Minas Gerais, em R\$46 milhões de toneladas por ano.."

Segundo dados obtidos no Plano de Regularização Fundiária Sustentável de Caeté, o Distrito de Morro Vermelho não possui nenhum parcelamento aprovado, 10 - ELABORAÇÃO DO TERMO DE REFERÊNCIA PARA O PLANO DIRETOR DE MORRO VERMELHO.

11 Informações disponíveis em: <http://saladeimprensa.vale.com/pt/versao_impressao/prt_detail.asp?tipo= $2 \& \mathrm{id}=19583>$. Acesso em: set. 2013. 
nem registrado em cartório. A ocupação é predominantemente anterior à Lei $\mathrm{n}^{\circ}$ $6.766 / 79$.

\section{A FORMA URBANA DO DISTRITO DE MORRO VERMELHO EM 2013}

O distrito localiza-se na zona rural, porém possui parcelamento e ocupação do solo com características urbanas. ${ }^{12} \mathrm{O}$ urbano e o rural se aproximam e se mesclam. Essa formação favoreceu a organização espacial linear ao longo de um caminho mais antigo, configurado por propriedades onde a testada adquiriu maior importância na divisão e apropriação da terra, com extensos terrenos vazios aos fundos - elementos espaciais marcantes e identificadores da paisagem atual.

A disposição das edificações no caminho tronco deve-se à limitação imposta pela encosta íngreme e pela presença do ribeirão Comprido (figura 6), fator que explica, também, o porquê de os lotes apresentarem testada maior que sua profundidade. Não há leitura clara de quarteirão.

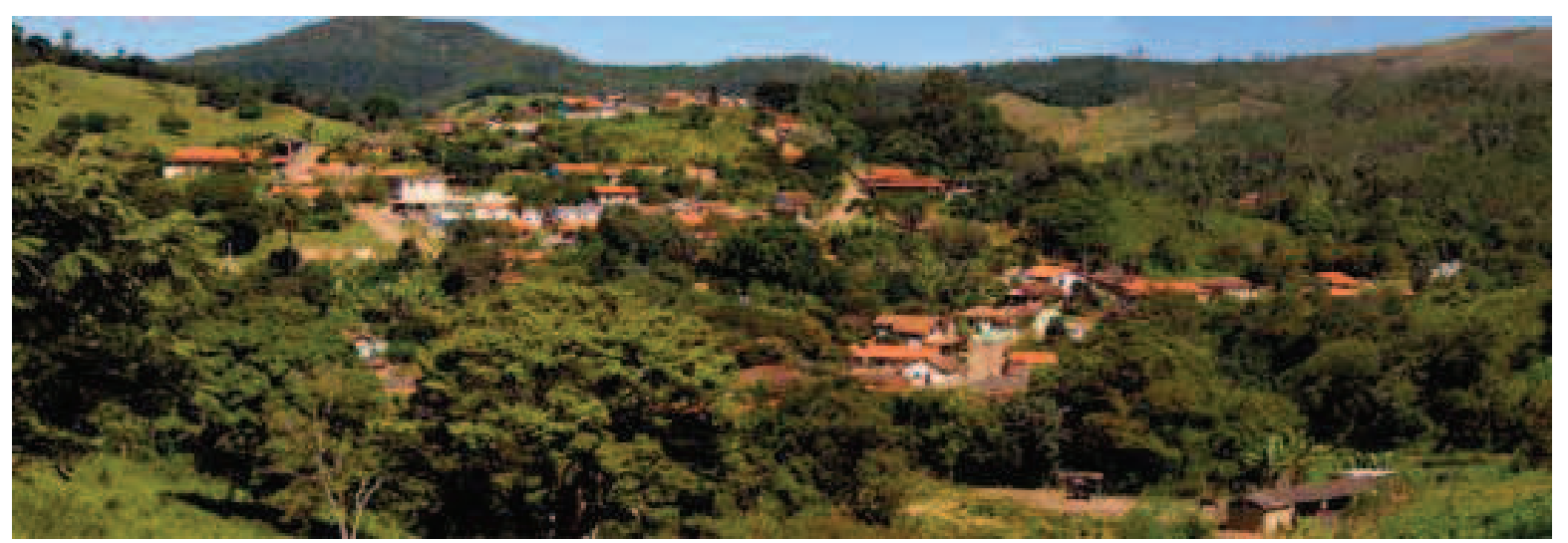

Figura 5 Vista geral do Distrito de Morro Vermelho.

Foto: Diana Mundim - 2013.

"tipo básico" mais recorrente é o que apresenta largura da fachada em torno de 10 a 12 metros, com partido horizontal e diminuto pé-direito. Encontra-se sempre alinhado em relação à rua, sem recuos frontal e lateral, elevado sobre embasamento de altura variável.

O tipo mais antigo possui estrutura em gaiola de madeira, com vedação em adobe. A fachada característica é alongada com sucessão de esquadrias, cujas marcações fazem parte da própria estrutura construtiva, com os cheios equivalendo à metade dos vazios ou a uma vez o vazio (figura 7).

12 Extraído do "Plano de Regularização Fundiária Sustentável de Caeté" elaborado em 2009 pela Fundação Israel Pinheiro e apresentado à Secretaria de Estado de Desenvolvimento Regional, Política Urbana e Gestão Metropolitana (Sedru) de Minas Gerais. 

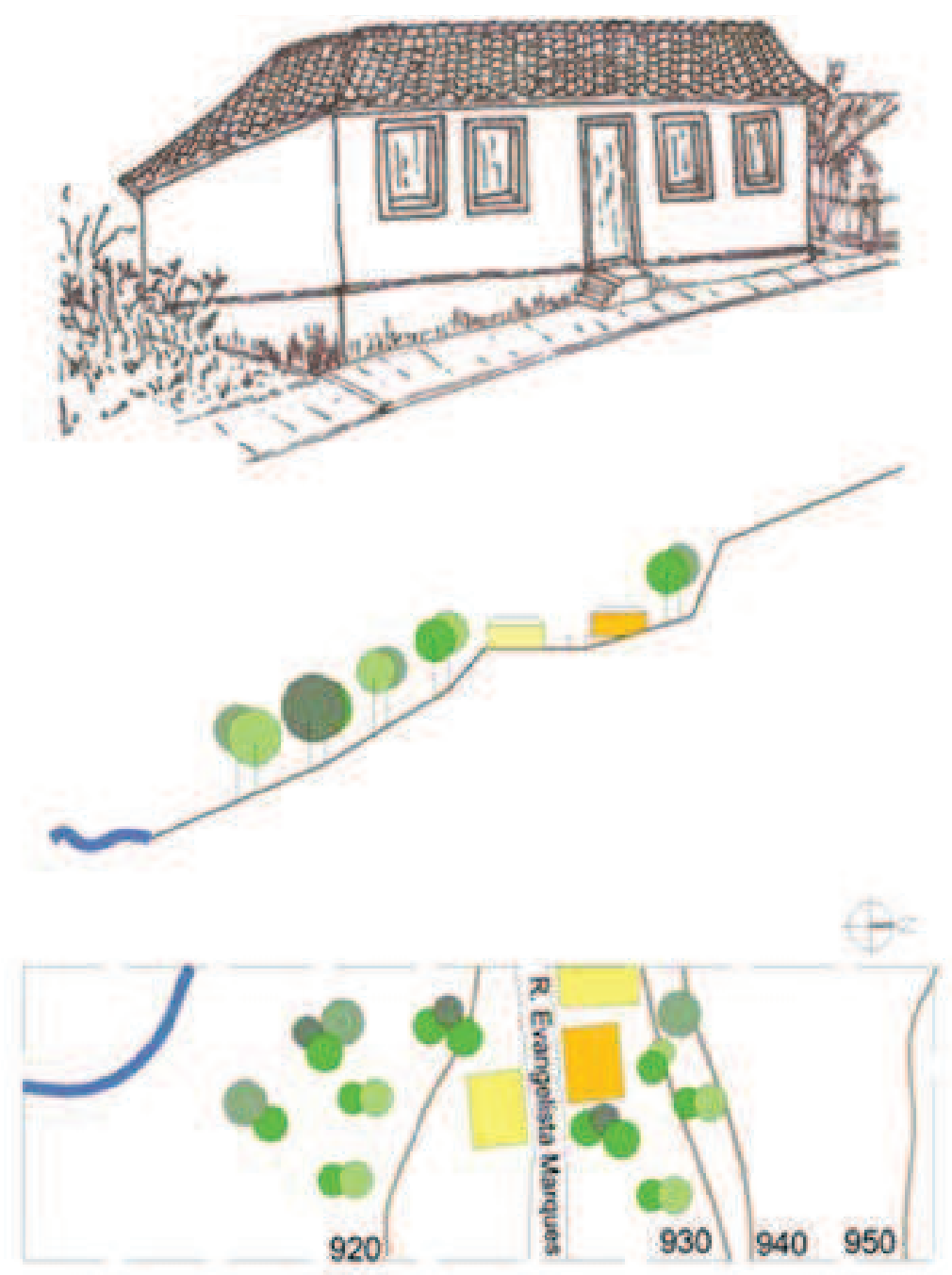

Figura 6 Exemplo de "tipo base" - fachada situa-se no intervalo de 10 a 12 m, implantação e corte esquemáticos. Fonte: Croquis de Luciane Faquineli, mai. 2013, esquema corte e implantação. Produzida pelas autoras - ago. 2013 - com base em mapa do PLAMBEL - 1977.
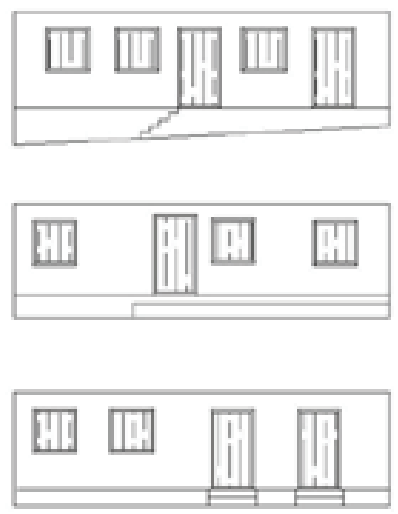
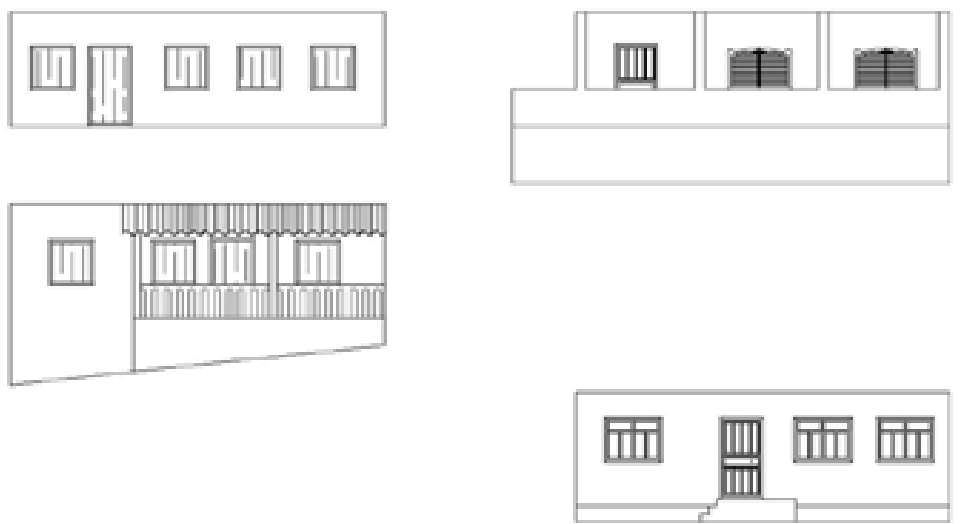

Figura 7 Variações do "tipo", cuja fachada situa-se no intervalo de 10 a 12 m: versões tradicionais e diacrônicas. Fonte: Produzida pelas autoras - maio/2013. 
Uma contraposição entre fotos antigas e as realizadas no levantamento de campo realizado em abril de 2013, durante a disciplina de Morfologia Urbana do MACPS (oferecida por Staël de Alvarenga Pereira Costa e Manoela Netto no $1^{\circ}$ semestre de 2013, no Mestrado de Ambiente Construído e Patrimônio Sustentável (MACPS) da EAUFMG), confirma a presença dos tipos destacados. Algumas edificações permaneceram ao longo do tempo ou sofreram variações, possibilitando a percepção do "processo tipológico" (figuras 8 e 9).
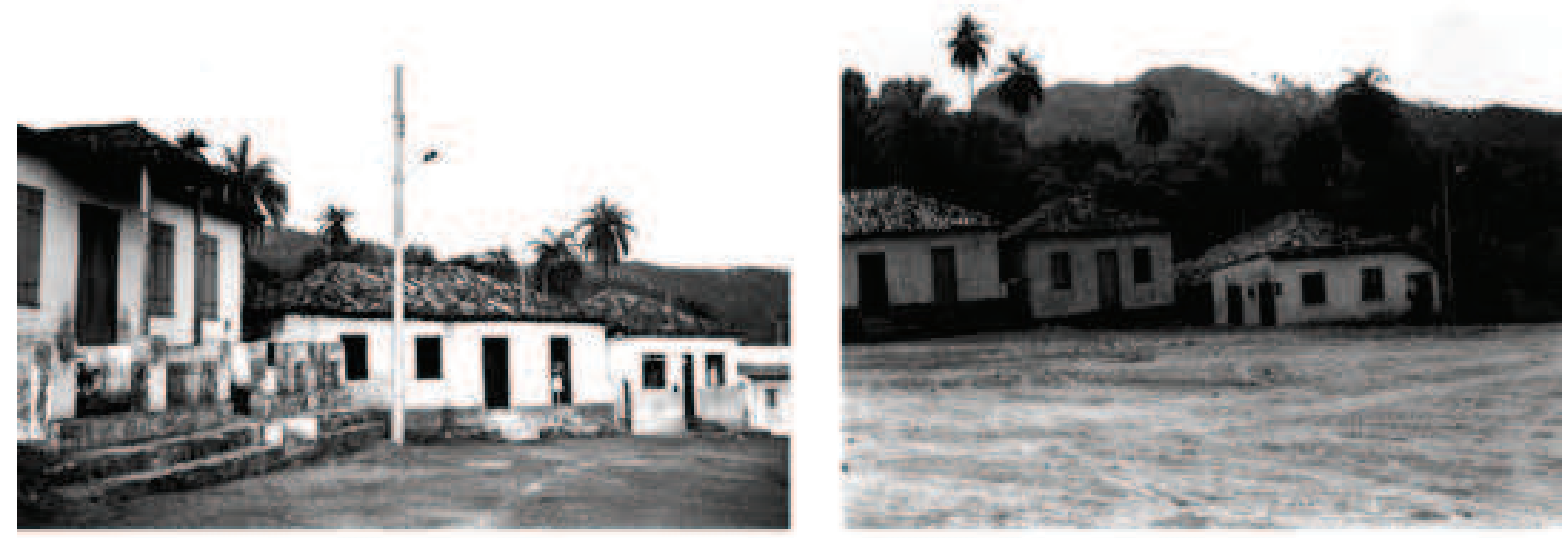

Figura 8 Aspectos do Largo da Matriz - 1984 (residências unifamiliares ao lado da Casa Paroquial). Fonte: Elizabeth Sales. Plano Diretor do Município de Caeté - 1984.

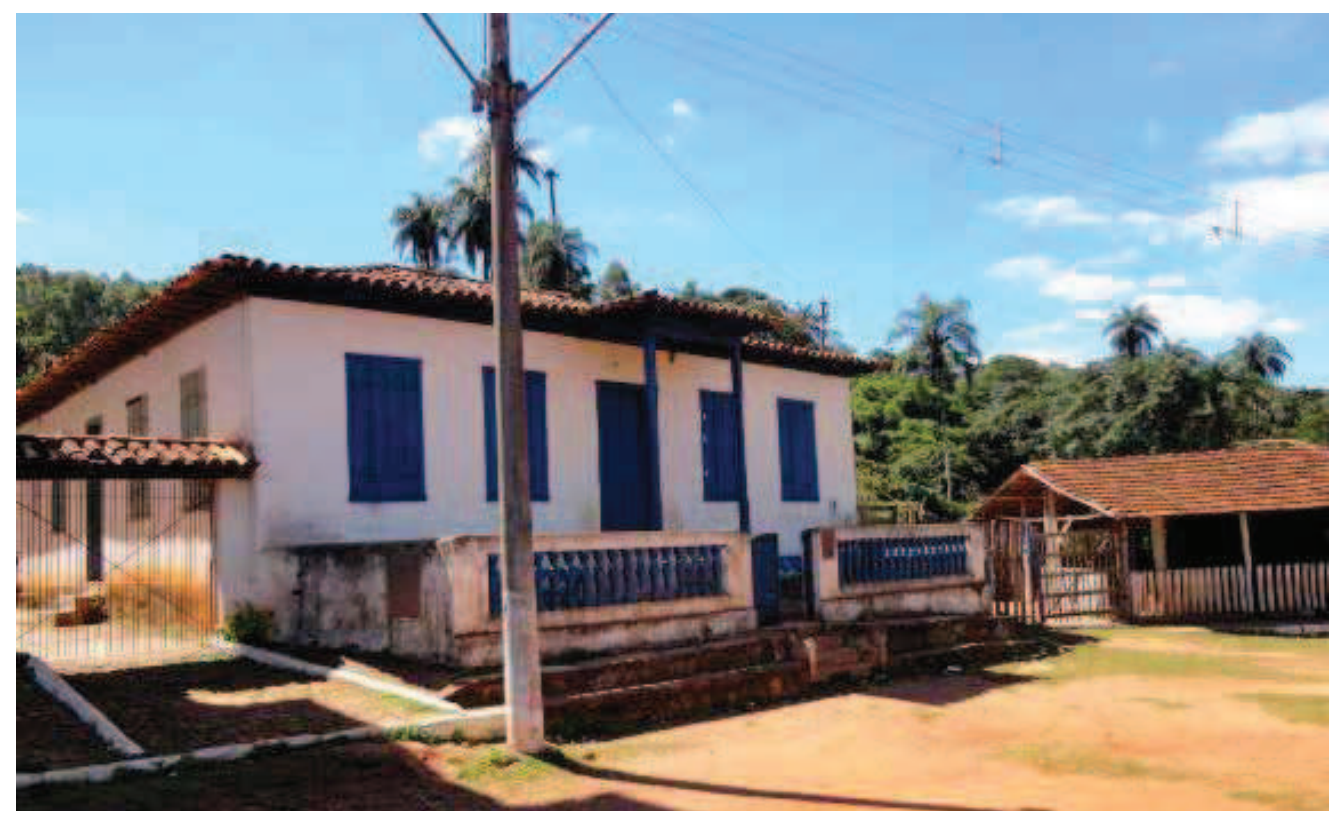

Figura 9 Casa Paroquial - mai. 2013. Foto: Bernardo Andrade - mai. 2013.

Nas figuras 10 a 12 é possível avaliar a evolução dos tipos pelas variações em relação à fachada (altimetria e inserção de alpendre) e ao uso. A comparação apresentada pelas fotos mostra a permanência ou evolução de alguns tipos. Observase que, apesar de Morro Vermelho não ter apresentado evolução urbana significativa 
- e que parece estar "parada no tempo" -, a paisagem adaptou-se para atender as demandas de uso do grupo social. Há, portanto, alterações no tipo básico, muitas vezes com adoção e inserção de novos materiais, visando ao baixo custo. Algumas dessas alterações são feitas de forma imediatista, sem considerar a unidade do conjunto.

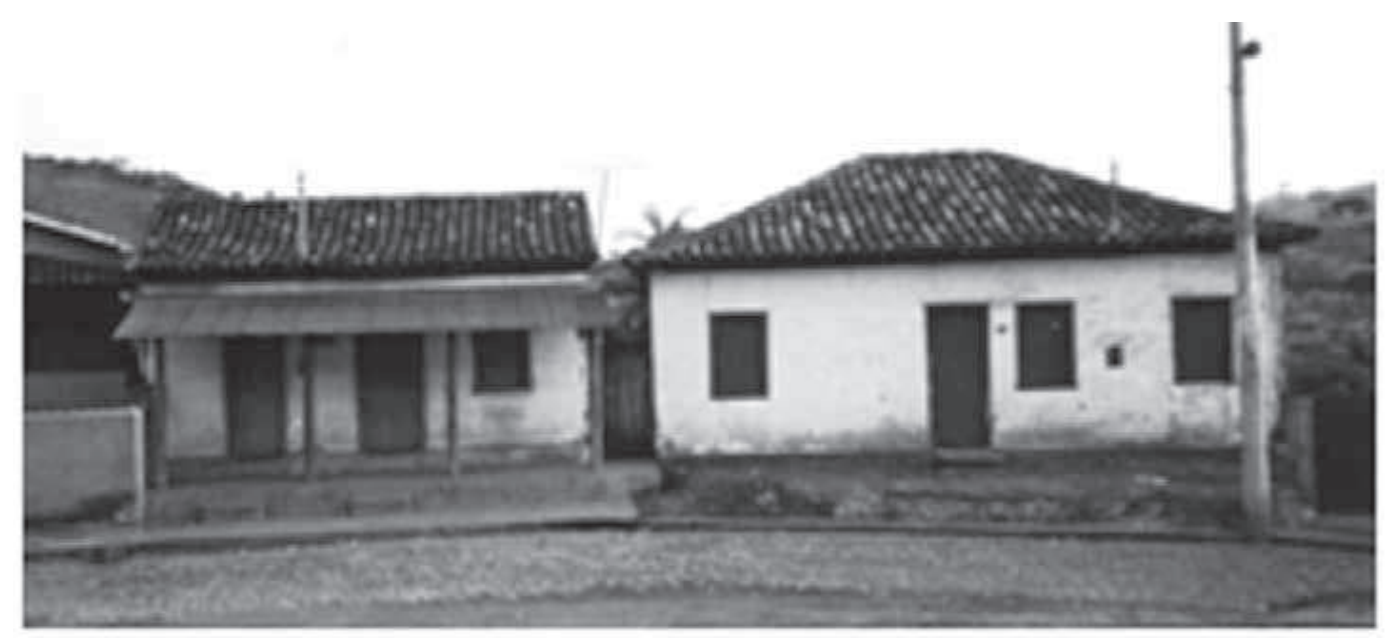

Figura 10 Aspectos do Largo da Matriz - 1984. Tipo 1: fachada de 6 a 8 metros (à esquerda). Tipo 2: fachada de 10 a 12 metros (à direita).

Fonte: Elizabeth Sales. Plano Diretor do Município de Caeté. 1984.
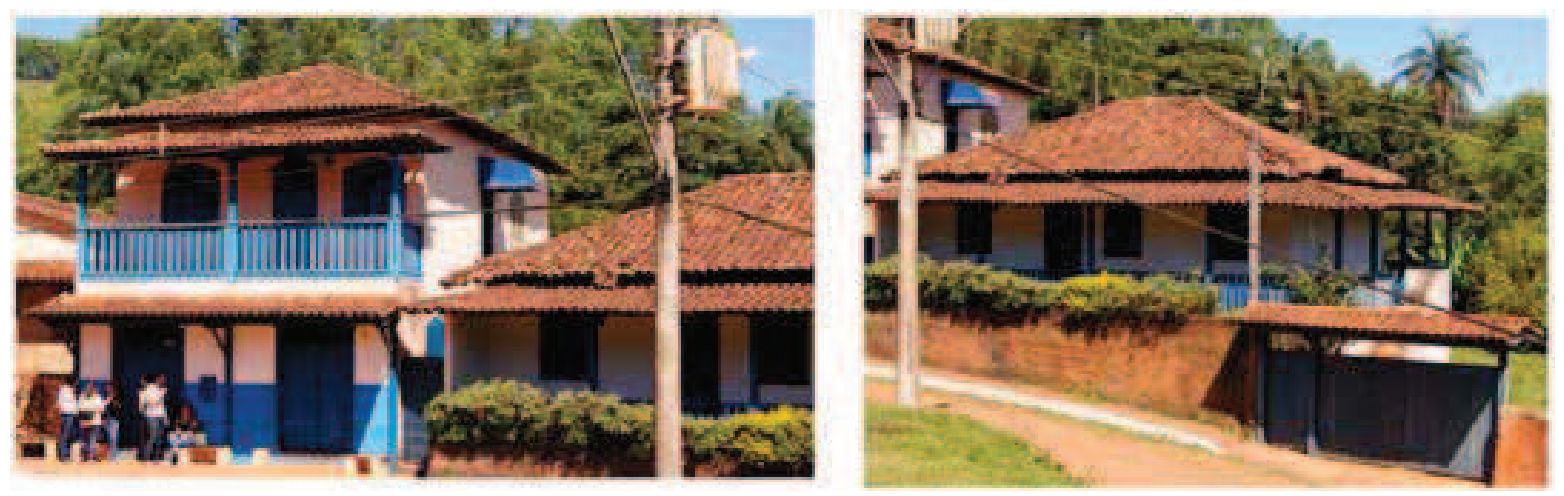

Figura 11 Variações do tipo 1, uso misto e acréscimo de outro andar (à esquerda), e variação do tipo 2, com inserção de varanda (à direita).

Foto: Diana Mundim - maio/2013.
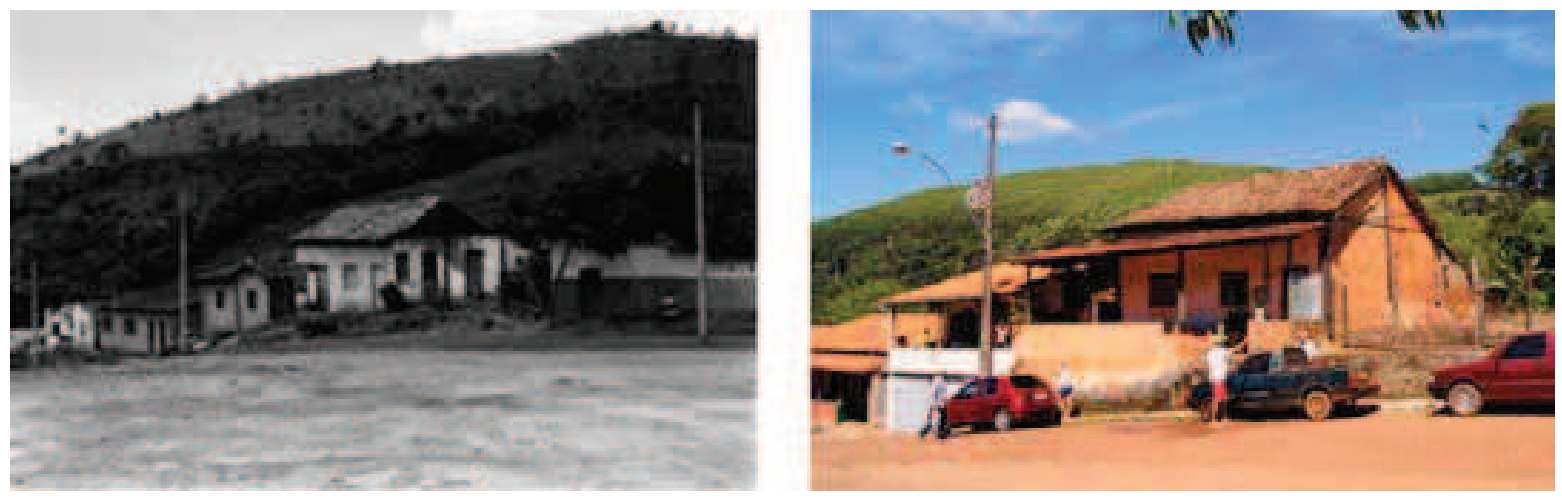

Figura 12 Morro Vermelho. Início da rua Dr. Antônio Mourão Guimarães: antes e depois.

Fonte: Plano Diretor do Município de Caeté - 1984. Diana Mundim - maio/2013. 


\section{MORRO VERMELHO E O ARRAIAL CURRAL DEL REI}

Nas figuras seguintes, podemos comparar a planta do distrito de Morro Vermelho (figura 15) e a ocupação urbana, em 2013, com a antiga planta (figura 14) da nova capital, Belo Horizonte, em 1897, cuja malha ortogonal se sobrepõe ao antigo arraial Curral Del Rei. Após análise da morfologia urbana de Morro Vermelho e de Belo Horizonte - quando Arraial Curral Del Rei -, percebe-se que o distrito apresenta conformação semelhante à dos arraiais do período colonial. Assim, pode-se dizer que Morro Vermelho permaneceu estagnado no tempo, como memória da gênese de uma formação que se desenvolveu e não se encontra mais, representando um exemplo vivo desses núcleos urbanos.
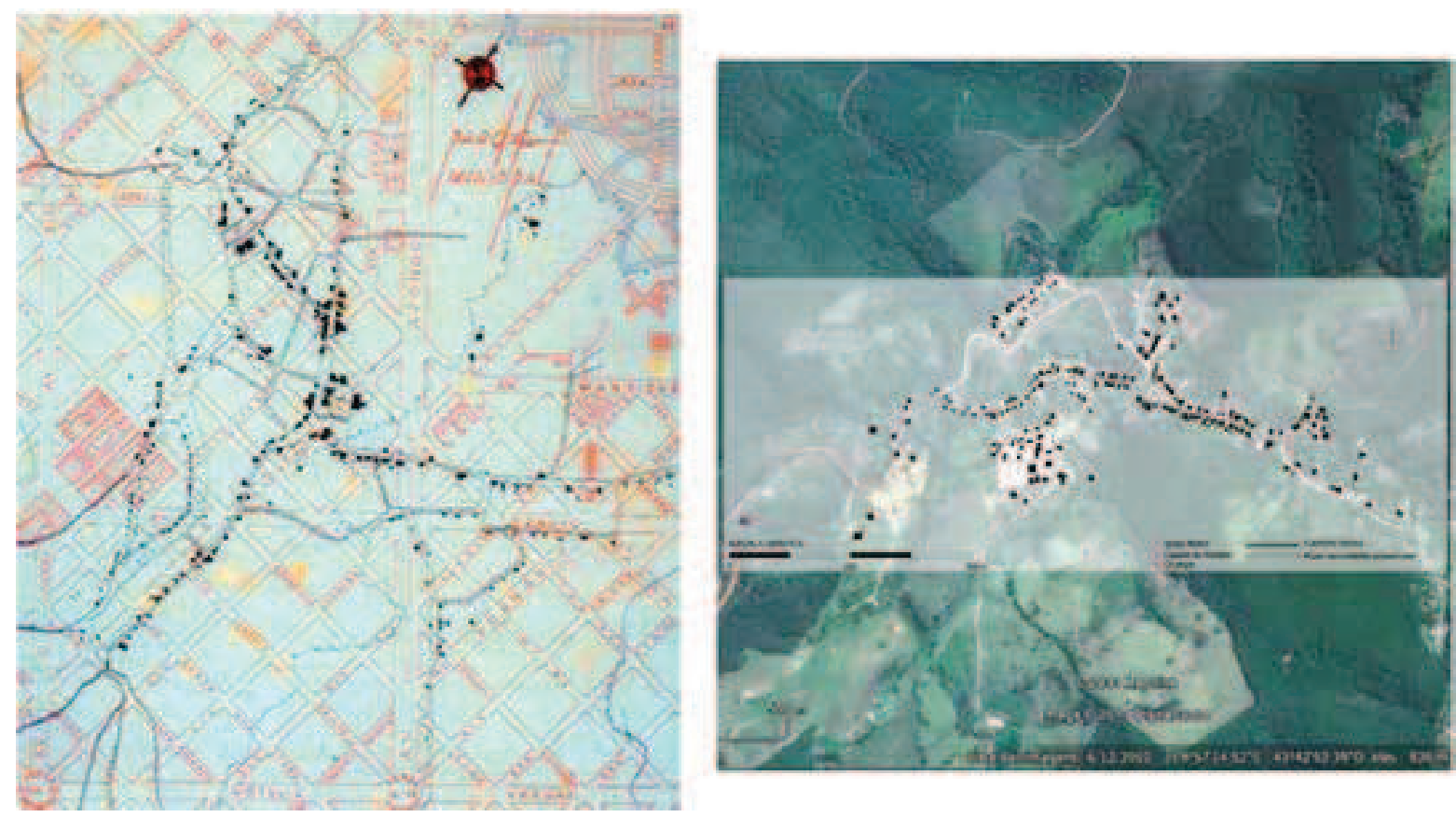

Figura 13 À esquerda, planta do arraial de Belo Horizonte sobreposta à malha ortogonal do novo plano - 1897. À direita, planta do distrito de Morro Vermelho sobreposta à foto aérea (Google Earth).

Fontes: À esquerda, Panorama de Belo Horizonte: atlas histórico. Sistema Estadual de Planejamento. Fundação João Pinheiro. Centro de Estudos Históricos e Culturais. Coleção Centenário. Belo Horizonte - 1997. À direita, produzida pelas autoras com base em foto aérea - Google Earth - julho/2013.

\section{CONSIDERAÇÕES FINAIS}

Os métodos apresentados pelas Escolas de Morfologia Urbana Inglesa e Italiana são de fundamental importância para o estudo da cidade enquanto habitat humano. Esses instrumentos possibilitam a análise das formas urbanas desde o seu início, como também das transformações subsequentes, apresentando tendências e apontando caminhos de interesse na preservação da memória e da paisagem.

Através do estudo da morfologia de Morro Vermelho, constatou-se a presença de características urbanas semelhantes aos povoados (protonúcleos) que não 
apresentam tecido urbano consolidado. As edificações concentram-se em torno do caminho tronco, origem de uma rota principal, formado no início da ocupação da região.

Essa constatação tem como valor o fato de Morro Vermelho ser um exemplo vivo da formação dos núcleos urbanos coloniais cujo distrito é ainda capaz de ser identificado como protonúcleo em 2013.

Além disso, foi possível observar a dessemelhança desse "agregado" em contraposição à metrópole desenvolvida na qual se insere. Morro Vermelho apresenta caráter único na RMBH, justamente por ter permanecido como que "congelado" no tempo, apresentando características originais das primeiras formações portuguesas em Minas Gerais.

Como o distrito é considerado o núcleo urbano mais potencialmente impactado pelas atividades previstas pela VALE na região, destaca-se a importância de um aprofundamento na compreensão dessa expressiva paisagem. O Projeto Mina Apolo, cujas futuras instalações industriais (com início previsto para 2014) situam-se a apenas $10 \mathrm{~km}$ do distrito de Morro Vermelho, representa parte dos $\mathrm{R} \$ 9,4$ bilhões referentes a investimentos, com previsão de gerar cerca de 9.930 empregos diretos e indiretos em sua construção - e outros 2,2 mil empregos, aproximadamente, na operação, potencializando a retomada do crescimento populacional e econômico no distrito.

A preservação de Morro Vermelho requer maior cuidado, para que também não venha a desaparecer, engolido pela modernização. Este trabalho pode ser disponibilizado para este fim, podendo o Laboratório da Paisagem da Universidade Federal de Minas Gerais, coordenado pela profa. Dra. Stäel de Alvarenga Pereira Costa, reverter para a sociedade os frutos de sua pesquisa.

\section{REFERÊNCIAS BIBLIOGRÁFICAS}

BELO HORIZONTE. Sistema Estadual de Planejamento, Fundação João Pinheiro, Centro de Estudos Históricos e Culturais. Panorama de Belo Horizonte: atlas histórico, 1997, Coleção Centenário. 104 p.

BRASIL. Lei n 6.766/79, de 19 dez. 1979. Dispõe sobre o Parcelamento do Solo Urbano e dá outras Providências. Brasília, Distrito Federal: Diário Oficial da União, 20 dez. 1979, p. 19457.

CANNIGIA, Gianfranco; MAFFEI, Gian Luigi. Architectural composition and building typology: interpreting basic building. Firenze: Alinea editrice srl., 2001. 252 p.

CONZEN, M.R.G. Alnwick, Northumberland: a study in town-plan analysis. Institute of British Geographers Publication 27. London: George Philip. 122 p.

INSTITUTO BRASILEIRO DE GEOGRAFIA E ESTATÍSTICA (IBGE). Censo populacional 2010. Disponível em: <http://www.ibge.gov.br/cidadesat/painel/painel.php?.codmun=311000 >. Acesso em: 9 jul. 2013.

LEVY, Albert. The typo-morphological approach of G. Cannigia and his school of thoughts. Journal of the International Seminar on Urban Form. Birminghan, v. 1, 1999a.

MACEDO, Silvio Soares. Quadro do paisagismo no Brasil. São Paulo: FAPESP: CNPq: Laboratório da Paisagem, 1999. 
MOULDON, Anne Marie Vernez. Urban morphology as an emerging interdisciplinary field. Journal Seminar of the International on Urban Form. Birminghan, Inglaterra, v. 1. 1997.

PEREIRA COSTA, Staël de Alvarenga. Transformações, conflitos, perdas e permanências na paisagem sul metropolitana de Belo Horizonte. 2004. 317 f. Tese (Doutorado em Arquitetura e Urbanismo) - Faculdade de Arquitetura e Urbanismo, Universidade de São Paulo, São Paulo, 2004.

PLANO DE REGULARIZAÇÃO FUNDIÁRIA SUSTENTÁVEL DOS MUNICÍPIOS DE CAETÉ, NOVA UNIÃO, RAPOSOS, RIO ACIMA E TAQUARAÇU DE MINAS. Produto 1 - Plano de Ação. Secretaria de Estado de Desenvolvimento Regional e Política Urbana. Ministério das Cidades. Belo Horizonte: 2008.

PREFEITURA MUNICIPAL DE CAETÉ. Memorial sobre o patrimônio histórico e cultural de Morro Vermelho. 2001

PREFEITURA MUNICIPAL DE CAETÉ. Fichas de Inventários de Estruturas Arquitetônica e Urbanísticas do Município de Caeté. Encadernado. Período 16 abr. 2003 a 15 abr. 2004 - ICMS Cultural - IEPHA. EX. 2005.

PREFEITURA MUNICIPAL DE CAETÉ. Dossiê de Tombamento da Capela do Rosário. Digitalizado. 2004.

TEIXEIRA, Maria Cristina Villefort et al. Os elementos tipomorfológicos das bordas metropolitanas de Belo Horizonte. Relatório final do projeto de pesquisa financiado pela Fundação de Amparo à Pesquisa do Estado de Minas Gerais (FAPEMIG). Universidade Federal de Minas Gerais, Escola de Arquitetura, Belo Horizonte, 2012.

\section{AGRADECIMENTOS}

As autoras agradecem o apoio recebido da Fundação de Amparo à Pesquisa de Minas Gerais - FAPEMIG, do Conselho Nacional de Desenvolvimento Tecnológico e Científico - CNPQ e da Coordenação de Aperfeiçoamento de Pessoal de Nível Superior - CAPES para o desenvolvimento desta pesquisa e apresentação deste artigo. 
Simone Marques de Sousa Safe, Luciane Raposo Faquineli e Staël de Alvarenga Pereira Costa 